\title{
The Well-Man Visit: Addressing a Man's Health to Optimize Pregnancy Outcomes
}

\author{
Jonathan N. Warner, MD, and Keith A. Frey, MD
}

Male health and health care before conception has received little attention by many physicians. Only recently has the importance of the health of men before conception been explored. The benefits of preconception care are important, including ensuring that all pregnancies are planned and wanted, improving the man's genetic and biologic contributions to the pregnancy, improving reproductive health and outcomes for female partners, improving the man's capacity for and understanding of parenthood, and enhancing the man's overall health through access to primary care. (J Am Board Fam Med 2013;26: 196-202.)

\section{Keywords: Men's Health, Preconception Care}

Male health and health care before conception has received little attention by many practitioners. It is also rare for a male patient to come to a clinic for preconception information. Only recently has the importance of preconception health for men been explored. ${ }^{1,2}$ The benefits of preconception care are important, including ensuring that all pregnancies are planned and wanted, improving the man's genetic and biologic contributions to the pregnancy, improving reproductive health and outcomes for female partners, improving the male's capacity and understanding of parenthood, and enhancing the man's overall health through access to primary care. ${ }^{2}$ Health care professionals evaluating and advising men regarding their overall reproductive health need a comprehensive framework, which is outlined herein.

\section{Evaluation}

\section{Reproduction Life Plan}

First, it is important to assess the goals and intentions of the male patient regarding reproduction

This article was externally peer reviewed.

Submitted 1 June 2012; revised 2 November 2012; accepted 7 November 2012.

From the Mayo Clinic, Thunderbird Primary Care Center, Scottsdale, AZ.

Funding: none.

Conflict of interest: none declared.

Corresponding author: Keith A. Frey, MD, Mayo Clinic, Thunderbird Primary Care Center, 13737 N 92nd St, Scottsdale AZ 85260 (E-mail: Frey.Keith@mayo.edu). goals. The Centers for Disease and Control and Prevention recommends that all men, women, and couples to have a reproductive life plan. ${ }^{3}$ This is defined as a set of goals about having children or not having children based on personal values and resources and a plan to achieve these goals. Like women, ${ }^{4}$ the male patient should be questioned regarding any previous children, the desire to have any more children, whether there has ever been trouble conceiving, and what time frame the couple has for conception. A recent study noted that $<10 \%$ of men can recall their primary care physician discussing preconception health care with them. ${ }^{5}$ If the couple is not currently interested in having children, it is important that the male patient be involved with contraception, and a discussion regarding proper methods should be addressed.

\section{Maximizing the Health of the Male Patient}

To maximize outcomes, herein we aid in the assessment of the male patient who is considering having a child. If the patient has been trying to conceive without results for some time, a formal fertility evaluation is warranted for both the male patient (by a male infertility specialist) and his partner.

\section{Medical and Surgical History}

As with all patient encounters, a detailed medical and surgical history is important for the evaluation of a man's reproductive health. Tables 1 and 2 list 
Figure 1. Discussion outline for male reproduction life plan. FSH, follicle stimulating hormone; HCG, human chorionic gonadotropin; TSH, thyroid stimulating hormone.

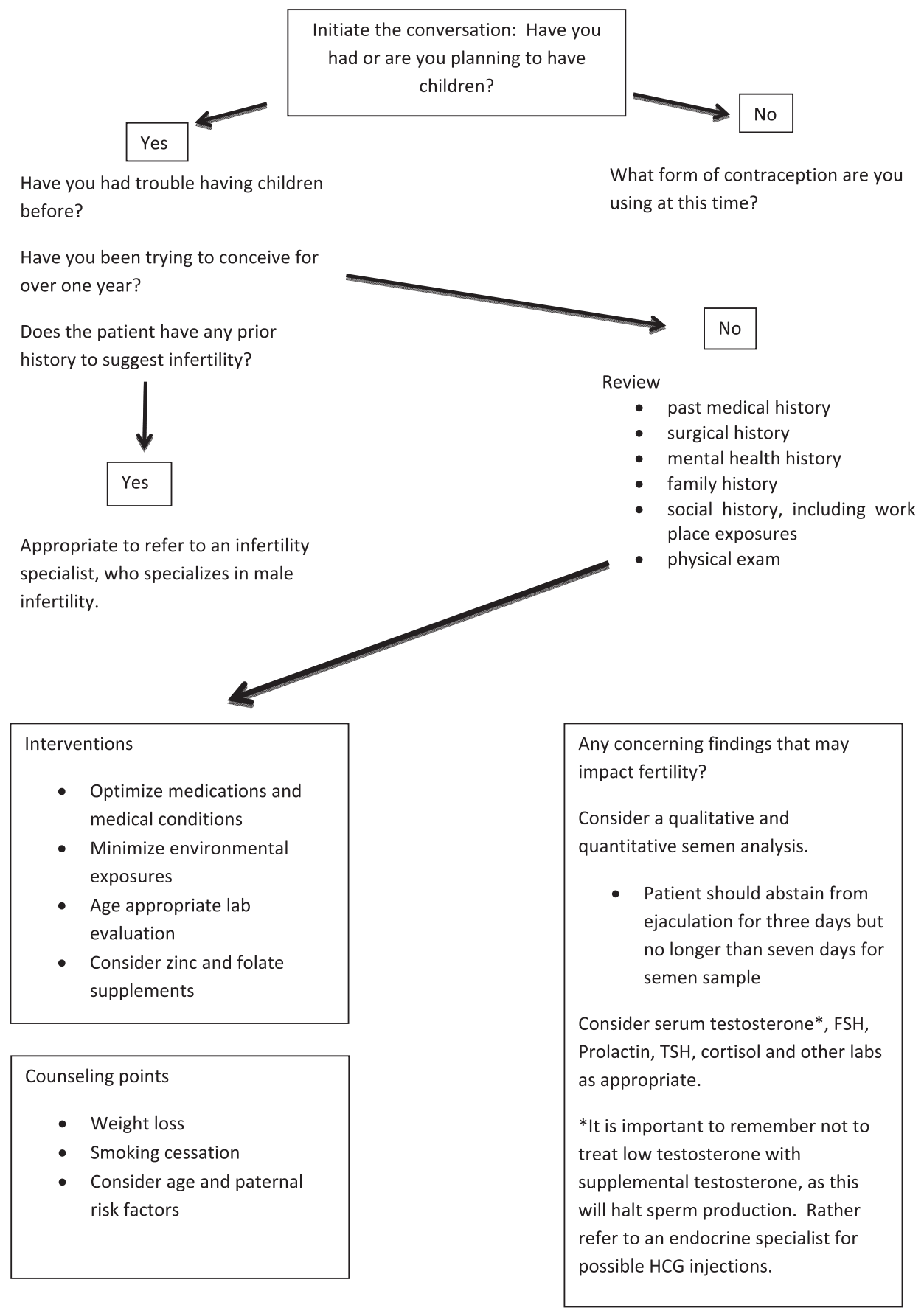

several medical and surgical conditions that are known to impact fertility. If these conditions exist, it is prudent to perform quantitative and qualitative analyses of semen. If abnormalities are found, referral to an infertility specialist is warranted. It is important to evaluate the patient's mental health as well. Although this may not directly impact the man's ability to father a child, there is evidence that the child of a father with depression may have behavioral and emotional developmental problems. ${ }^{21}$

\section{Medications}

The patient's medication history should be evaluated, including past and current prescription medications, nonprescription medications, herbal remedies, and 


\section{Table 1. Medical Conditions Associated With Infertility}

Cryptorchidism, testicular torsion, and trauma ${ }^{6}$

Postpubertal mumps orchitis ${ }^{7}$

Congenital adrenal hyperplasia

Obesity $^{8}$

Diabetes and poor glycemic control ${ }^{9}$

Erectile dysfunction ${ }^{10,11}$

Multiple sclerosis and spinal cord injury ${ }^{12}$

Hyper or hypothyroidism ${ }^{13}$

Varicocele $^{14}$

Prostatitis, epididymitis, sexually transmitted diseases ${ }^{15}$

Malignancies (Hodgkin ${ }^{16}$ and testicular cancer ${ }^{17}$ ) and any endocrine or metabolic effects of cancer ${ }^{18}$

recreational drugs. If the patient is taking medications that are known to impact fertility (Table 3), an alternative should be sought or the patient should be monitored appropriately. Medications may alter the hypothalamic-pituitary-gonadal axis, impair libido, affect erectile function, or have a direct toxic effect on the sperm.

\section{Family History and Genetic Risks}

As part of the family history, a detailed genetic history should be obtained. Because sex-linked or autosomal disorders may skip generations, a 3-generation history is important. Conditions to screen for include cystic fibrosis, which impairs infertility through a congenital absence of the vas deferens, ${ }^{28}$ and Klinefelter syndrome, which impairs fertility through sclerosis of the seminiferous tubules, resulting in azoospermia and small testicles. ${ }^{29}$ Families with intersex disorders should lead to the evaluation of the possibility of androgen receptor abnormalities.

\section{Social History}

As noted earlier, the risks of tobacco, alcohol, and elicit drug use can directly affect spermatogenesis and impact erectile function. However, a social history is also important to determine whether the patient is exposed to environmental hazards, including ionizing radiation, radiant heat, pollutants in the diet, lead, mercury, dichlorodiphenyltrichloroethane, carbon disulfide, ethylene glycol ethers, dibromochloropropane, polycyclic aromatic hydrocarbons, polychlorinated biphenyls, dioxins, phlates, and acrylamide. $^{30}$

A review of patient's hobbies should also be performed. Woodworking with oils used to finish furniture, painting, pottery with lead-based glazes, stained glass work, and gun cleaning and shooting may lead to toxic exposures to lead and other heavy metals that are harmful to sperm production.

\section{Physical Examination}

A thorough physical examination should be performed as part of the preconception evaluation. This includes screening for hypertension and obesity through body mass index measurements. Overall body habitus should also be evaluated because it can offer clues about androgen abnormalities. Tall stature, gynecomastia, and decreased body hair could suggest Kleinfelter syndrome. Hyperpigmentation may be a sign of underlying adrenal insufficiency; whereas abdominal striae, increased abdominal girth, and enlargement of the fat pad along the back of the neck and collar bone could be suggestive of Cushing syndrome. Excess sweating and essential tremor could be indicative of hyperthyroidism.

An examination of visual fields should be performed; hemianopsia could indicate a pituitary adenoma. The thyroid gland should be evaluated because enlargement could be indicative of underlying hyperor hypothyroidism.

Gynecomastia may be a sign of Kleinfelter disease, excess estrogen, or androgen insensitivity, which may be associated with infertility. Underlying respiratory disease may be indicative of ciliary disease such as Kartagener syndrome, cystic fibrosis, or Young syndrome, which may inhibit fertilization through absence or obstruction of the vas deferens. A cardiovascular examination should be performed to identify any underlying arterial compromise, which may contribute to erectile dysfunction.

An abdominal examination should be performed to evaluate for any surgical scars, particularly in the lower abdomen or inguinal region, for any evidence of a previous operation that may have affected the patency of the vasa. Heptomegaly may indicate un-

\section{Table 2. Surgical Conditions Associated With Infertility}

Inguinal hernia repairs ${ }^{19}$

Scrotal or pelvic surgery

Retroperitoneal surgery in the setting of testicular cancer ${ }^{20}$

Incision of the bladder neck and transurethral resection of the prostate 


\begin{tabular}{ll}
\hline Medication & Effect \\
Exogenous testosterone & Decreased spermatogenesis \\
Androgen supplements & Impaired HPG axis \\
5 - $\alpha$ reductase inhibition & ED, impaired sperm production ${ }^{22}$ \\
$\alpha$-blockers & Retrograde ejaculation \\
$\begin{array}{l}\text { Cimetidine, spirinolactone, and ketoconazole } \\
\text { Erythromycin, neomycin, tetracycline, nitrofurantoin, and }\end{array}$ & $\begin{array}{l}\text { Direct inhibition of androgen production } \\
\text { gentamycin }\end{array}$ \\
$\begin{array}{l}\text { Selective serotonin receptor inhibitors, monoamine oxidase } \\
\text { inhibitors, lithium, and phenothiazines }\end{array}$ & Decreased libido, ED, and alteration of the HPG axis ${ }^{23}$ \\
$\begin{array}{l}\text { Chemotherapeutic agents } \\
\text { Marijuana, }{ }^{24} \text { cocaine, }{ }^{25} \text { alcohol, }{ }^{26} \text { and tobacco }{ }^{27}\end{array}$ & $\begin{array}{l}\text { Direct impairment of spermatogensis } \\
\text { May impair the HPG axis, spermatogenesis, and erectile function }\end{array}$ \\
\hline
\end{tabular}

ED, erectile dysfunction; HPG, hypothalamic-pituitary-gonadal.

derlying hepatic dysfunction, which may impair the metabolism of sex steroids.

A genital examination should be performed (Table 4), beginning with the phallus. Penile lesions could indicate an underlying sexually transmitted disease. Hypospadius, penile curvature, or chordee may impact the delivery of semen during intercourse. The scrotal skin and contents should be evaluated. The presence of scars could indicate previous scrotal surgery, which may impact patency of the vas deferens. Small testicles could indicate testicular failure, either primarily as is seen in Kleinfelter syndrome, or secondarily as seen with use of exogenous testosterone. Normal testicular size is $4 \times 3 \mathrm{~cm}$ or a $20-\mathrm{mL}$ volume. ${ }^{31}$ Undescended testicles or absent testicles should also be noted. Testicular masses may indicate an underlying neoplasm. Epididymal tenderness may be indicative of untreated epididymitis, which can affect sperm delivery. The presence of the vas deferens should be evaluated to rule out congenital absence of the vas deferens. Vasal nodularity or thickening could indicate a prior infection such as tuberculosis, whereas thickening may be indicative of obstruction. Finally, the patient should be examined in the supine and standing positions to determine the presence of a varicocele. Varicoceles are seen in $15 \%$ of normal men and are present in $19 \%$ to $41 \%$ of men with primary infertility and up to $81 \%$ of those with secondary infertility. ${ }^{14}$

\section{Laboratory Testing}

Basic screening, as recommended by the U.S. Preventive Service Task Force, should be offered to all male patients. This includes screening for lipid disorders beginning at age 35 (and for men ages 20 to 35 if they have diabetes, a family history of coronary artery disease or familial hyperlipidemia, or multiple risk factors for coronary heart disease) and screening for diabetes. ${ }^{32}$

Targeted laboratory evaluation can be directed toward specific clinical signs and symptoms. Prolactin levels may be checked if there is any evidence of bitemoporal hemianospia. Thyroid function tests should be ordered if there are signs and symptoms of hyper- or hypothyroidism. Adrenal function tests may be necessary with any signs of Addison or Cushing syndrome. Liver function testing should be completed if there is evidence of hepatomegaly. Testosterone, estrogen, folliclestimulating hormone, and luteinizing hormone should be evaluated if there are small testicles, gynecomastia, enuchoid body habitus, or signs of androgen resistance.

\section{Recommendations for Health Promotion}

Achieving and maintaining a healthy weight is the starting point for discussion of health promotion. Obesity has a number of detrimental health effects. In fact, every $20 \mathrm{lb}$ overweight can lead to a $10 \%$ increase in the odds of infertility. ${ }^{8}$ As part of the preconception evaluation, overweight and obese men should be counseled on the health and fertility benefits of weight loss; they should set goals and be offered the resources to achieve those goals. This may include referral to a nutritionist, a structured weight loss program, and promoting regular exercise.

Stress reduction is also important to emphasize in male patients. Although the mechanisms are not fully understood, there is a clear impact of stress on 
Table 4. Physical Examination

\begin{tabular}{|c|c|}
\hline Examination & Possible Condition \\
\hline \multicolumn{2}{|l|}{ General } \\
\hline Tall stature & Kleinfleter syndrome \\
\hline Long arms & Kleinfelter syndrome \\
\hline Absence of body hair & Adrenal disease \\
\hline Hyperpigmentation & Adrenal disease \\
\hline Obesity & $\begin{array}{l}\text { Impaired testosterone and high } \\
\text { estrogen }\end{array}$ \\
\hline \multicolumn{2}{|l|}{ HEENT } \\
\hline Bitemporal hemianopsia & Pituitary adenoma \\
\hline Goiter & Thyroid disease \\
\hline Anosmia & Kallman syndrome \\
\hline \multicolumn{2}{|l|}{ Chest } \\
\hline Gynecomastia & $\begin{array}{l}\text { Kleinfelter syndrome or HPG } \\
\text { axis defect }\end{array}$ \\
\hline Buffalo hump & Adrenal disease \\
\hline $\begin{array}{l}\text { Respiratory rhales and } \\
\text { crackles }\end{array}$ & Cystic fibrosis or ciliac disease \\
\hline \multicolumn{2}{|l|}{ Abdomen } \\
\hline Surgical scars in the pelvis & $\begin{array}{l}\text { Possible nerve damage or vasal } \\
\text { damage }\end{array}$ \\
\hline Inguinal scars & Vasal obstruction \\
\hline Striae & Adrenal disease \\
\hline Truncal obesity & Adrenal disease \\
\hline Hepatomegaly & Liver disease \\
\hline \multicolumn{2}{|l|}{ Genitals } \\
\hline Penile lesions & $\begin{array}{l}\text { Possible STD, which impacts } \\
\text { fertility }\end{array}$ \\
\hline Inguinal adenopathy & $\begin{array}{l}\text { Possible infection or } \\
\text { malignancy }\end{array}$ \\
\hline Impalpable vas deferens & $\begin{array}{l}\text { Possible CBAVD or cystic } \\
\text { fibrosis }\end{array}$ \\
\hline Vas deferens nodularity & Possible vasal obstruction \\
\hline Varicocele & Impairs fertility \\
\hline Scrotal scars & $\begin{array}{l}\text { Possible testicular or vasal } \\
\text { injury }\end{array}$ \\
\hline Epididymitis, prostatitis & $\begin{array}{l}\text { Active infection can impair } \\
\text { fertility }\end{array}$ \\
\hline
\end{tabular}

CBAVD, congenital absence of the vas deferens; HEENT, head, ears, eyes, nose, and throat; HPG, hypothalamic-pituitary-gonadal; STD, sexually transmitted disease.

sperm morphology ${ }^{33}$ and concentration ${ }^{34}$ and decreasing testosterone. ${ }^{35}$ The reason for these changes is believed to be mediated by impacts on the hypothalamic-pituitary-gonadal axis secondary to increased release of epinephrine and corticotrophin-releasing hormone, which impacts the natural pulsatility of luteinizing hormone. ${ }^{36,37}$ Approaches to stress reduction include regular exercise, proper sleep habits, and proper nutrition.

The benefits of avoidance of tobacco, alcohol, and recreational drugs have been noted. Providers should also encourage those patients with a profession with hazardous environmental exposures to take appropriate precautions to minimize risk. This includes the use of leaded aprons for those with regular exposure to $\mathrm{x}$-rays and proper use of gloves and masks when exposed to harmful toxins. Nutritional recommendations are not only an important part of helping a patient maintain a healthy weight and reducing stress, but certain nutrients actually have been shown to affect the viability of sperm; zinc sulfate and folic acid have shown a positive effect on sperm production. ${ }^{38}$

\section{Additional Considerations}

Men with findings during a physical examination that suggest hormonal or testicular abnormalities should be referred to an infertility expert. In addition, the couple who has been attempting unsuccessfully to conceive should undergo an infertility evaluation. ${ }^{39}$ It is vital that male patients be included in such an infertility evaluation. ${ }^{39,40}$

Male patients should also be counseled regarding the growing evidence of increased risks associated with advanced paternal age. The risk of a child with schizophrenia is twice as likely if the father is 45 or older compared with those in their 20 s and 3 times more likely after the paternal age of $50 .{ }^{41}$ Autism is 5.75 times more likely if the father is aged 40 or older compared with those men who father a child when they are younger than $40 .{ }^{41,42}$ Autosomal dominant disorders also have been associated with advanced paternal age, including achondroplasia, Marfan syndrome, and osteogenesis imperfecta. ${ }^{43}$

\section{Conclusions}

Preconception care and planning is important for improving pregnancy outcomes, ensuring all pregnancies are planned and wanted, and enhancing the health of female partners and, particular to this review, of the male patient. The preconception examination is an excellent window to promote not only reproductive health but also to discuss overall health issues with the male patient. This includes promotion of proper nutrition and regular exercise, treatment and prevention of diseases, stress reduction, and avoidance of dangerous behaviors.

\section{References}

1. Frey KA. Male reproductive health and infertility. Prim Care 2010;37:643-52, x.

2. Frey KA, Navarro SM, Kotelchuck M, Lu MC. The clinical content of preconception care: preconcep- 
tion care for men. Am J Obstet Gynecol 2008;199: S389-95.

3. Johnson K, Posner SF, Biermann J, et al; CDC/ ATSDR Preconception Care Work Group; Select Panel on Preconception Care. Recommendations to improve preconception health and health careUnited States. A report of the CDC/ATSDR Preconception Care Work Group and the Select Panel on Preconception Care. MMWR Recomm Rep 2006;55(RR-6):1-23.

4. Files JA, Frey KA, David PS, Hunt KS, Noble BN, Mayer AP. Developing a reproductive life plan. J Midwifery Womens Health 2011;56:468-74.

5. Frey KA, Engle R, Noble BB. Preconception healthcare: what do men know and believe? J Mens Health 2012;9:25-35.

6. Puri P, Barton D, O’Donnell B. Prepubertal testicular torsion: subsequent fertility. J Pediatr Surg 1985;20:598-601.

7. Werner CA. Mumps orchitis and testicular atrophy; a factor in male sterility. Ann Intern Med 1950;32: 1075-86.

8. Sallmen M, Sandler DP, Hoppin JA, Blair A, Baird DD. Reduced fertility among overweight and obese men. Epidemiology 2006;17:520-3.

9. Padron RS, Dambay A, Suarez R, Mas J. Semen analyses in adolescent diabetic patients. Acta Diabetol Lat 1984;21:115-21.

10. McCulloch DK, Campbell IW, Wu FC, Prescott RJ, Clarke BF. The prevalence of diabetic impotence. Diabetologia 1980;18:279-83.

11. Sexton WJ, Jarow JP. Effect of diabetes mellitus upon male reproductive function. Urology 1997;49: 508-13.

12. Sonksen J, Biering-Sorensen F. Fertility in men with spinal cord or cauda equina lesions. Semin Neurol 1992;12:106-14.

13. Velazquez EM, Bellabarba Arata G. Effects of thyroid status on pituitary gonadotropin and testicular reserve in men. Arch Androl. 1997;38:85-92.

14. Agarwal A, Deepinder F, Cocuzza M, et al. Efficacy of varicocelectomy in improving semen parameters: new meta-analytical approach. Urology 2007;70:532-8.

15. Aitken RJ, De Iuliis GN. Value of DNA integrity assays for fertility evaluation. Soc Reprod Fertil Suppl 2007;65:81-92.

16. Rueffer U, Breuer K, Josting A, et al. Male gonadal dysfunction in patients with Hodgkin's disease prior to treatment. Ann Oncol 2001;12:1307-11.

17. Petersen PM, Skakkebaek NE, Vistisen K, Rorth M, Giwercman A. Semen quality and reproductive hormones before orchiectomy in men with testicular cancer. J Clin Oncol 1999;17:941-7.

18. Costabile RA, Spevak M. Cancer and male factor infertility. Oncology (Williston Park) 1998;12:55762, 565; discussion 566-8, 570.
19. Shin D, Lipshultz LI, Goldstein M, et al. Herniorrhaphy with polypropylene mesh causing inguinal vasal obstruction: a preventable cause of obstructive azoospermia. Ann Surg 2005;241:553-8.

20. Kedia KR, Markland C, Fraley EE. Sexual function after high retroperitoneal lymphadenectomy. Urol Clin North Am 1977;4:523-8.

21. Ramchandani P, Stein A, Evans J, O'Connor TG. Paternal depression in the postnatal period and child development: a prospective population study. Lancet 2005;365:2201-5.

22. Giuliano F. Impact of medical treatments for benign prostatic hyperplasia on sexual function. BJU Int 2006;97(Suppl 2):34-8; discussion 44-5.

23. Nudell DM, Monoski MM, Lipshultz LI:. Common medications and drugs: how they affect male fertility. Urol Clin North Am 2002;29:965-73.

24. Close CE, Roberts PL, Berger RE. Cigarettes, alcohol and marijuana are related to pyospermia in infertile men. J Urol 1990;144:900-3.

25. Hurd WW, Kelly MS, Ohl DA, Gauvin JM, Smith AJ, Cummins CA. The effect of cocaine on sperm motility characteristics and bovine cervical mucus penetration. Fertil Steril 1992;57:178-82.

26. Muthusami KR, Chinnaswamy P. Effect of chronic alcoholism on male fertility hormones and semen quality. Fertil Steril 2005;84:919-24.

27. Vine MF, Tse CK, Hu P, Truong KY. Cigarette smoking and semen quality. Fertil Steril 1996;65: 835-42.

28. Anguiano A, Oates RD, Amos JA, et al. Congenital bilateral absence of the vas deferens. A primarily genital form of cystic fibrosis. JAMA 1992;267: $1794-7$.

29. Lanfranco F, Kamischke A, Zitzmann M, Nieschlag E. Klinefelter's syndrome. Lancet 2004;364:273-83.

30. Bonde JP. Male reproductive organs are at risk from environmental hazards. Asian J Androl 2010;12: 152-6.

31. Charny CW. The spermatogenic potential of the undescended testis before and after treatment. J Urol 1960;83:697-705.

32. Guide to Clinical Preventive Services, 2nd edition. Rockville, MD: Agency for Healthcare Research and Quality; 2010. Available from: http://odphp.osophs. dhhs.gov/pubs/guidecps/. Accessed January 3, 2013.

33. Giblin PT, Poland ML, Moghissi KS, Ager JW, Olson JM. Effects of stress and characteristic adaptability on semen quality in healthy men. Fertil Steril 1988;49:127-32.

34. Zorn B, Auger J, Velikonja V, Kolbezen M, Meden-Vrtovec H. Psychological factors in male partners of infertile couples: relationship with semen quality and early miscarriage. Int $\mathrm{J}$ Androl 2008;31:557-64.

35. Nilsson PM, Moller L, Solstad K. Adverse effects of psychosocial stress on gonadal function and insulin 
levels in middle-aged males. J Intern Med 1995;237: 479-86.

36. McGrady AV. Effects of psychological stress on male reproduction: a review. Arch Androl 1984;13:1-7.

37. Schweiger U, Deuschle M, Weber B, et al. Testosterone, gonadotropin, and cortisol secretion in male patients with major depression. Psychosom Med 1999;61:292-6.

38. Wong WY, Merkus HM, Thomas CM, Menkveld R, Zielhuis GA, Steegers-Theunissen RP. Effects of folic acid and zinc sulfate on male factor subfertility: a double-blind, randomized, placebo-controlled trial. Fertil Steril 2002;77:491-8.
39. Jose-Miller AB, Boyden JW, Frey KA. Infertility. Am Fam Physician 2007;75:849-56.

40. Kolettis PN. Evaluation of the subfertile man. Am Fam Physician 2003;67:2165-72.

41. Malaspina D, Harlap S, Fennig S, et al. Advancing paternal age and the risk of schizophrenia. Arch Gen Psychiatry 2001;58:361-7.

42. Reichenberg A, Gross R, Weiser M, et al. Advancing paternal age and autism. Arch Gen Psychiatry 2006; 63:1026-32.

43. Stewart AF, Kim ED. Fertility concerns for the aging male. Urology 2011;78:496-9. 